\title{
Accessibility Indicator for a Trails Network in a Nature Park as part of the Environmental Assessment Framework
}

\begin{abstract}
The natural heritage of parks is an important resource within the framework of sustainable development. Plans, projects and activities concerning park management form the basis for evaluations that rely on indicator systems to keep the evolution of pressure factors and the conditions of habitats and protected species under control. The aim of this study is to contribute to the provision of tools to analyse and evaluate the social impact of a Nature Park in terms of the accessibility and usability for all of the network of pedestrian paths within it.

The study proposes an analysis methodology and an indicator of the "environmental accessibility of the pedestrian network" which enables us to measure some aspects of accessibility such as: the ease of getting around, comfort and security for all types of users, with the maximum degree of autonomy improving the quality of the visitor's experience of the park.

A spaces configuration and performance based analysis methodology was used, and the 'accessibility for all' indicator was developed in relation to the conduct of users, based on expert knowledge and the involvement of stakeholders. The results are highlighted using maps.

There is still a long way to go before methodologies and operational procedures for this type of accessibility analysis can be set out, and the case studies research can provide an important contribution. The article reports on the application of the proposed methodology to the case study of the Natural Park of Migliarino, San Rossore and Massaciuccoli in Tuscany (Italy).
\end{abstract}

Keywords: Environmental Accessibility. Impact Indicators. Natural Park. Space Syntax. Barrier free environment

Graphical Abstract
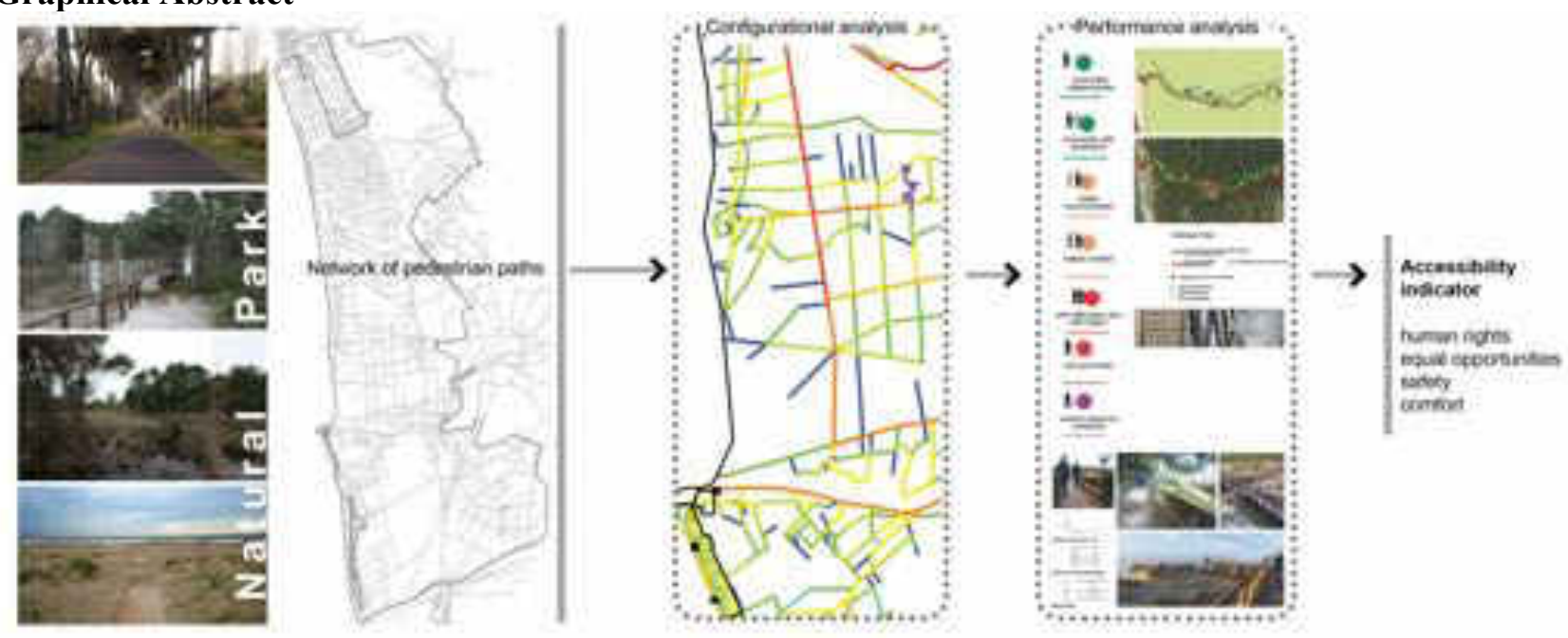

\section{Highlights}

- The natural heritage of parks represents an important social resource

- Accessibility for all to Nature Parks ensures equal opportunities, safety and well-being

- An Accessible Park means creating a network of clear paths with no physical barriers

- The paper presents a new methodology to assess the accessibility of the paths network in a park

- An indicator of accessibility for all in a Nature Park is provided 


\section{Introduction}

\subsection{Environmental and social sustainability of Natural Parks}

The natural heritage of parks is an important resource within the framework of sustainable development at both global and local level. The environmental approach to sustainable development has had the virtue of highlighting the naturally available resources representing the natural capital, in an economy that assigns nature the capacity to provide ecosystem services for development (Costanza et al., 1997; Millenium Ecosystem Assessment, 2005; Kareiva et al., 2011) and from this perspective it should be both protected and enhanced. Since the 1960-70s the environmental culture has promoted a vision aimed at protecting the eco-compatibility of economic growth (Carson, 1962) and promoting the enhancement of environmental systems that produce biodiversity and biocapacity (IUCN UNEP WWF, 1980). However, from the end of the twentieth century and with the start of the twenty-first the issue of sustainable development saw social aspects resurface, United Nations in 2000 adopted the Millennium Development Goals (A/RES/55/2, 2000) already detailed in the Bruntland report (WCED, 1987), to be understood not only as a social consequence of environmental transformations. The social issue has placed increasing attention not only on the global but also the local dimension of the natural capital (landscape, territory) and ecosystem services (ground, air, water, food) causing the environmentalist culture and the regional planning culture to converge (Magnaghi, 1998) into the concept of nature as capital, as an asset to be enhanced, capable of producing ecosystem services, and as a heritage, an asset available to society (Dale et al., 2001). The ecosystem services also include cultural, aesthetic, spiritual, educational and recreational ones (Millennium Ecosystem Assessment 2005) ${ }^{1}$ and, as argued by Burkhard et al. (2012) as concerns the Salzau Message (2010) on "Sustaining natural capital and ecosystem services," the ecosystem services must also be assessed from a social and economic point of view. The social aspect and its dimension, even local, require us to consider the "system of players" present in the region (Moine, 2006).

In the context of natural capital and ecosystem services, heritage represented by a protected area, according to the IUCN (International Union for Conservation of Nature) definition, is represented by "a clearly defined geographical space, recognised, dedicated and managed, through legal or other effective means, to achieve the long-term conservation of nature with associated ecosystem services and cultural values." (Dudley, 2008:8).

Protected areas are internationally classified by IUCN to take account of biodiversity values alongside social and economic values, in particular for the most directly affected communities (IUCN, 2017). According to both the IUCN classification and other classifications, for example that of MAB UNESCO (UNESCO, 2017), a fundamental distinction is made between a nature reserve and wilderness area on the one hand and, on the other, areas where sustainable use and management of the resources is possible. In the latter, the organization that manages the Park has the task of protecting the natural heritage and at the same time also providing services to enhance the park for its users and the local community. An important prerequisite of this aspect is the accessibility and usability of some parts of the park itself, without coming into conflict with habitat and species conservation, ensuring that individuals and the local community are able to make use of it as local property and as a common good for the benefit of humans and personal health, personal well-being, and social well-being.

\subsection{Background and research questions}

\footnotetext{
${ }^{1}$ Millenium Ecosystem Assessment Reports 2005 Global Assessment, Chapter 1 MA Conceptual Framework p.29: "Cultural services are the non-material benefits people obtain from ecosystems through spiritual enrichment, cognitive development, reflection, recreation, and aesthetic experiences."
} 
Plans, projects and activities concerning park management already form the basis for evaluations, for instance the assessment of the impact they could have on the integrity of habitats and species (in the EU see Habitats Directive 92/43/EEC and Directive 2009/14/EC) or those conducted within the environmental management systems of the parks themselves (Ielasi et al., 2003; ENEA, 2001). These evaluations use indicator systems to keep the evolution of pressure factors and the conditions of habitats and protected species under control, in order to define conservative, improvement, compensatory or recovery-oriented management strategies, but also for the environmental evaluation of the service and production activities going on within the park (Gondran, 2012). Some of these indicators concern actions aimed at using the protected area, as proposed by tools and indicators known as the "internal road network" or "trial accessibility" (Ielasi et al., 2003; Clius et al., 2012; Torricelli, 2015), going on to contemplate specific aspects of the social management of a park.

Within this framework of environmental and social evaluation, the research outlined below proposes the development of a methodology to analyse the pedestrian trail network inside a park capable of developing an "environmental accessibility of the network" indicator. The European Disability Strategy 2010-2020 defines Accessibility "as meaning that people with disabilities have access, on an equal basis with others, to the physical environment, transportation, information and communications technologies and systems (ICT), and other facilities and services." So the environment, hence the use of the term 'environmental accessibility,' plays an important role in enabling everyone to identify, reach, understand and use the places and services in comfort and security (EC, 2010; Lauria 2017; Aragall, 2003). The accessibility of public spaces intended for recreational activities, and in particular of Natural Parks in areas where use is admitted, is an important component in the context of equal opportunities, human rights, and the security and well-being of people (Rapley, 2013; Farrington, 2007). "Accessibility within a park" (Levi Sacerdotti et al., 2010) has to do with performances such as: the ease of getting around, comfort and security for all types of users, with the maximum degree of autonomy possible for everyone, improving the quality of the visitor's experience of the park. The aim is to overcome a vision of standard accessibility, or vice versa comprised of special measures for specific users (AA.VV, 1988; MATTM, 2003), and to provide tools to analyse and assess the social impact of parks in terms of accessibility and usability for all (Solinas, 2004; Nesi and Bagnato 2005; Steffan 2012). The issue of the accessibility of protected areas has been addressed in European regulations, and in Italy in regional regulations and it has given rise to the promotion of programmes and projects such as that of Aspromonte National Park in the Calabria Italy Region (Nesi and Bagnato, 2005 ) or of the Protected Area of Lazio Italy Region (Regione Lazio, 2006). But few studies have helped to develop tools and methods for the design and implementation of accessibility for all (Nesi and Bagnato, 2005; US Forest Service, 2013; Zeller et al., 2012).

As with many methods used to analyse the social impact (deriving, for example, from the 2016 Sustainable Development Goals of UNDP - United Nations Development Programme), indicators are also useful in the case of territorial and network accessibility. The indicator can be both a performance and an impact indicator at the same time. As regards the relationship between performances and impacts in social issues, the differentiation is often not applicable or of little significance as argued, for example, in the field of S-LCA - Social Life Cycle Assessment- (Dreyer et al., 2006; Grießhammer te al. 2006; Chipi-Shrestha et al., 2015). Moreover, a social indicator can be expressed in negative or positive terms, that is in terms of damage or protection and promotion. The concept of positive impacts (or positive benefits) or negative impacts has arisen in the field of the Social Impact Assessment (SIA) (Esteve et al., 2012) and of the S-LCA (Di Cesare et al., 2015). 
Using this background as a basis, we developed a performance/impact analysis of the social issues arising from the "internal path network accessibility" of a natural park posing the following research questions:

- which technical analyses of the network of pedestrian paths in a natural park allow us to measure the accessibility for all along the same paths?

- is it possible to develop an indicator responsive to and driven by user needs?

- how can this type of indicator be communicated in reports to ensure the information reaches and is understood by the stakeholders.

\section{Methodological framework to define an accessibility indicator for the trails network}

The formulation of indicators to assess the sustainability of products, processes, services and organizations is generally conducted within frameworks useful for defining the categories and their relationships, as in the DPSIR model (EEA 1999), or the development process starting with measures, accounting and inventorying, as in the LCA methods (ECJRC-IES, 2010) or the process of managing the same indicators (identification, monitoring and reporting), as in the social responsibility of organizations (ISO, 2010a). In any case, it is useful to start with a definition of the term indicator in general and in the specific research or application context and to describe a reference framework or path that guides the selection of related parameters.

As regards the different definitions of the term, we agree with Bowen and Riley (2003) in assuming the consolidated definitions developed and disseminated by the Organisation for Economic Co-operation and Development (OECD, 1998): "The OECD has argued that a successful indicator should: reduce the number of measures which normally would be required for an exact presentation of a situation; and simplify the process of communication to managers, stakeholders and communities" (Bowen and Riley, 2003).

With specific regard to problems pertaining to pedestrian trail networks in a park, the indicator we proposed to develop was to meant to measure the accessibility and usability performance, the social impact value of which derives from the fact that it refers to the diverse needs of people and the value that each person may attribute to the use of the paths within the park itself. That is, the indicator must measure the accessibility performance of the network of trails in the park with reference to the needs of people with varying abilities to move around and orient themselves. This performance is socially relevant because it gives everyone equal opportunities and it respects human rights, from the perspective of ensuring the safety and well-being of people.

Defined conceptually, the type of indicator and the steps in the process to develop it are summarized below:

- identify the factors driving the selection of specific observations and measures correlated to the performance/impact under observation

- determine the data collection method and whether relevant data is already available

- determine the data analysis method, and the development of the indicator and check its coherence, robustness and repeatability

- create an indicator validation system in relation to the impact to be measured

- define the indicator reporting method and check whether it is comprehensive to stakeholders and how it is communicated to them.

For the selection of observations and measures to be carried out, the method we have followed starts with the definition of the boundaries of the system observed and the identification of the categories of stakeholders, referring to the recent UNEP/SETAC documents for the S-LCA applicable also in this case although reported to products and services. In the 
issue under analysis, the boundaries of the system observed are represented by: external transport and external access hubs, attraction hubs, namely the internal points of interest, the internal paths for the network sub-systems, and the external paths complementing the circuits or for pedestrian access (Fig. 1). Among the various types of users to consider, it was decided to refer to visitors with their multiple and specific needs. In order to apply the comparative evaluation indicator to parks of the same type, or to support decision-making in the management of the park, it was considered useful to refer to the definition of 'functional equivalent' (ISO 2010b; EN 15804:2012): this describes the object of the study and enables the aspect studied to be referred to the functional requirements for data normalisation and their effects. One definition of functional equivalent in the case in question takes into consideration, in succession according to the order of presentation, the following functional criteria:

- the type of area protected, for example a protected area with the sustainable management of resources (according to the classifications referred to above, IUCN or UNEP-WCMC classification (2014-2015)

- the applicable size class as compared, for example, to the European Park system

- the extension of the network of pedestrian paths accessible to the public within the park

- the external access hubs to the network.

Other criteria may be adopted to define the functional equivalent, which are particularly useful in assessing the relationship between the accessibility of the protected area and the protection of biodiversity, such as: the percentage ratio of the extension of the protected core area and the total park area including the "buffer areas," or criteria based on recognised indicators such as those proposed by Europe for monitoring biodiversity in the Streamlining European Biodiversity Indicators 2010 (SEBI, 2010, 2012).

As regards the data collection and analysis method, we proposed the sequenced use of space configurational and performance analysis techniques applied to the pedestrian trail system that visitors may use inside the park and the footpaths along the edges just outside of the park's boundaries. The analysis process followed was broken down as illustrated below.

Initially, all of the public trails and footpaths and their hubs usable by pedestrians were surveyed and mapped. A GIS platform was then used to construct a model representing the network of trails, dividing each trail into segments ${ }^{2}$ using the configurational analysis criteria set out in the Space Syntax methodology (Hillier, 2007; Al-Sayed et al., 2014). The configuration is the group of relations among the elements comprising the system, based on geometric and topological relationships and it deals with users' cognitive attributes (Penn, 2003; Hillier and Iida, 2005) by indirectly being able to measure the probability that users will move along specific itineraries. The adaptation of the configurational analysis to the trail network in a park was one of the challenges developed by the method during the testing of the case study (see paragraph 3.2.1). In the configurational analysis, a sub-group of trails and footpaths with a higher level of probability of use was selected. The level of probability was defined on the basis of the Choice parameter of the Space Syntax Analysis (see paragraph 3.2.1), identifying the "high probability of choice of the trails by visitors" as a choice value that exceeds the threshold of $70 \%$ of the maximum value calculated in the case in question. The trails defined as the most likely were then subjected to a performance analysis. The performance analysis was a survey of physical and perceptive person-environment conflict conditions and had the purpose of assessing the criticality conditions for the most common and significant requirement profiles of users. To this end, parameterization criteria were used for user profiles and environmental conflict conditions based on: the distance and travel time along a path for different types of users based on the type and degree of ability and the aids they use, taken from literature (Knoblauch et al., 1996; Gates et al., 2006)

2 By segment we mean each section of a linear path delimited by either a change in direction or intersection with other lines. 
(Tab.1) and direct findings; criteria for accessibility requirements, practicability, the provision of services and support, taken from direct observations made by involving the different interested users and observing their behaviour and reactions; technical criteria relating to the geometric and technical components of the paths (width, unevenness, paving etc.); regulatory criteria or specifications with which to comply.

\begin{tabular}{|l|c|c|c|c|}
\hline Type & $\mathbf{m} / \mathbf{s e c}$ & Source & km/ half day & $\mathbf{k m}$ / day \\
\hline Excursionist walker & 1.05 & Bibliographic $^{(2)}{ }^{(3)}$ & 11.3 & 22.6 \\
\hline Excursionist on electric wheelchair & 1.15 & Bibliographic $^{(1)}$ & 12.4 & 24.8 \\
\hline Excursionist on wheelchair & 0.75 & Bibliographic $^{(1)}$ & 8.1 & 16.2 \\
\hline Excursionist expert walker & 1.30 & Bibliographic $^{(2)}{ }^{(3)}$ & 14.0 & 28.0 \\
\hline Blind with guide dog & 0.82 & Test measurement & 8.85 & 17.7 \\
\hline Blind with assistant & 0.70 & Test measurement & 7.5 & 15 \\
\hline Blind with stick & 0.49 & Test measurement & 5.3 & 10.6 \\
\hline Person on electric wheelchair & 1.01 & Test measurement & 10.92 & 21.84 \\
\hline Person on wheelchair & 0.81 & Test measurement & 8.8 & 17.6 \\
\hline
\end{tabular}

Tab. 1 - Distance and travel time along a path for different types of users based on the type and degree of ability and the aids they use. The bibliographic sources consulted are: (1) Aragall and Sagramola, 2003; (2) Gates et al., 2006; (3) Knoblauch et al., 1996

The survey on which the performance analysis is based was supported and carried out using survey sheets for the individual trails attributing a qualitative evaluation validated with the stakeholders for the different types of visitors.

Based on these analysis, overlaid maps were developed that enabled the identification of the probability levels and the critical issues for use belonging to each segment of a trail or footpath. First of all, probability and difficulty scales were defined and marked on two maps of the paths observed: one identifies the most accessible paths based on a configurational analysis, and another identifies the most difficult paths for the different types of users contemplated. Overlapping the two scales that measure the degree of accessibility (configurational and performance-based) on a single map produces a representation of the accessibility indicator for each path in the trail network map.

For each segment of path the environmental accessibility indicator is expressed by this formula:

$G_{\text {apath }}=1 / b^{*} A$

Where $G_{\text {apath }}$ is the path level of environmental accessibility, resulting from the level of probability of actually being used $(I)$, and the criticality of the access performances $(A)$ weighted (coefficient $\mathrm{b}$ ) in relation to the relevance that it intends to give to different user requirement profiles.

The accessibility indicator for each individual path is shown by a scale of colours that highlight the segments of the route with different levels of accessibility on a map of the park's trails and footpaths (see paragraph 4).

Numerically speaking, a mean environmental accessibility indicator for the park can be calculated by making a weighted average of the $G_{\text {apath }}$ based on the length of each segment in relation to the total length of the network. We can also calculate on the map how many kilometres of the network of paths in the park detected have been assessed with a $G_{\text {apath }}$ greater than a set value. The average numerical indicators or those that exceed the threshold can be used to compare the different parks characterized by a similar functional equivalent or to support plans to improve the accessibility conditions in a certain park. 
The indicators of single paths are validated, as regards the $I$ parameter, according to the Space Syntax configurational theories (Hillier and Hanson, 1984; Hillier, 2007; Hillier and Raford, 2010; Penn, 2008), and as regards the $A$ parameter and the $\mathrm{b}$ weighting with the involvement of stakeholders and users as described in paragraph 3.2.2.

The maps that represent the values of the indicators of the individual paths in the space with the use of colour represent a tool for easy comprehension and can also be communicated on the park websites.

\section{Case study application and data analysis}

\subsection{The MSRM Natural Park: boundaries and users}

The environmental accessibility analysis and indicator was applied to the Natural Park of Migliarino, San Rossore and Massaciuccoli (MSRM) in Tuscany, Italy. The application was used as a test to clarify the research questions and develop methods of analysis and assessment.

The MSRM Park is a publicly owned entity, with full autonomy as concerns politics, economics, finances, organization of services, supervision and security, planning, promotion and environmental education, under the auspices of the Region of Tuscany and the involvement of five municipal administrations. The park covers a surface area of 234 $\mathrm{km}^{2}$ of which $142 \mathrm{~km}^{2}$ have been classified as a protected area. 55\% of the park is privately owned. The territory is divided into seven Estates with historic origins. The park comprises natural and semi-natural coastal areas as well as agricultural ecosystems, for the most part made up of woods, wet zones, sand dunes and watershed. The proportion of urbanized or partially urbanized areas is about 5\%, but urban and infrastructural pressure at the borders of the park make the park an island under siege. The value of the environment has been highlighted by the designation of sites inside the Park as Natura 2000 sites and by its position in a MAB UNESCO area (Habitats Directive 92/43/EEC).

The internal pedestrian trail networks of the park are made up of the historical network of trails and roads, interrupted by the Serchio and Arno rivers. There is also a system of roadways with high-intensity vehicular traffic and a railway passing through the Park. The pedestrian trails and bicycle paths comprise the public access network for leisure and recreational activities, differentiated based on conservation restrictions. Inside the park there are (managed directly by the local administration, contractors, associations or businesses): four visitor's centres, a restaurant, a hotel, a guest house, small residences for social tourism, a historic complex set up with classrooms, laboratories, congress and study centre, a school and a church with quarters. The local administration has begun many social initiatives for the use of the park, such as horse therapy, equipped learning trails, which may also be used by the disabled, foot trails, didactic observatories and laboratories as well as information and documentation centres. Over five hundred businesses, including beach facilities, farms, farm tourism establishments, reception centres and food services operate in the park. The local administration has approximately fifty employees working there (Fig. 2).

More than 50,000 visitors per year, including from outside the region, regularly use the park's facilities. There is an annual increase target of 4,000, however, those from nearby areas who regularly access the free entry zones such as the marina actually number many more.

As it is not a nature reserve, the park has a high number of marked paths. This study has reconstructed the system of public and pedestrian trails and footpaths usable by visitors inside the park.

The first step, before the subsequent analysis to determine the accessibility indicator, was the mapping of the public trails and footpaths and their hubs using the GIS platform. A large part of park area is private property and at times not accessible to visitors. To determine which pedestrian streets are really accessible, inspections of the park area were 
carried out with the aid of Google Earth, maps owned by the park management, and interviews conducted with staff from the technical office. Overall, the path system modelled contains almost $1240 \mathrm{~km}$ of road systems (modelled in around 8,000 segments), of which $810 \mathrm{~km}$ (around 4,500 segments) are within the administrative boundaries of the park. The boundary of the system for the construction of the relative spatial models was determined as follows: the network of all the paths accessible to the public, therefore excluding paths in private areas or protected natural areas where transit is forbidden; the paths used to enter the park; the stretches of road outside the park which lead in and out of the park area.

\subsection{Methods and data analysis}

The two analysis methods were used to construct the accessibility indicator. The first is configuration and the second is performance-based. The results of the two analysis methods were integrated to develop the environmental accessibility indicator for the park (Fig.3).

\subsubsection{The configurational analysis}

The paths system was then subjected to a configurational analysis according to the Space Syntax methodology and techniques.

A few theoretical and methodological problems arise when a configurational analysis is applied to a network of paths in a natural park. The theory of the experiential landscape (Thwaites and Simkins, 2007) highlights the spatial dimension of the human experience of the landscape and that some dimensions of the configuration of the spaces can be beneficial to the experience of the outdoor environment. People experience the park by walking through it. We can consider the park as being made up of equipped areas and paths, the former are limited areas for passing the time and engaging in activities, whereas the latter are used for circulation and enjoyment of the park through the experience of walking. There are studies that apply the Space Syntax theory to urban parks (Zhai and Baran, 2013) as well as parts of the city (Hillier and Vaughan, 2007), and from them we can draw indications above all for the construction of a spatial model representative of a natural situation such as that of a park. There are however important differences linked above all to the presence of natural elements such as vegetation and waterways and the presence of marked trails. Vegetation can be high and low, dense and less dense and therefore its presence represents a barrier that does not contribute to the creation of specific boundaries between the spaces to be taken into consideration for the analyses, like a building in an urban environment would. Moreover, plants and water elements at times permit great visibility, but not accessibility. This visibility varies depending on the areas (woodland, clearings, mixed) and on the season. Moreover, in a natural park visitors use the marked trails mainly for three reasons: i) in a very large area such as big parks they reduce the risk of getting lost, ii) visitors are safer, iii) they do not create damage to animals or plant species.

Taking these aspects into account, the circumscription of the spaces to be analysed was done in consideration of all the trails marked within the park and indicated on tourist maps, which are highly recognizable paths for users and represent a clear guide for tourists who wish to explore the park.

The construction of the spatial model using the Space Syntax configurational methodology was done by drawing an axial line on each previously catalogued path. The most suitable technique for modelling such a large area is the axial line which contains within it the definition "longest line of sight and movement" (Hillier, 2007). This visibility was verified on site with reference to the marked trails. In the model the equipped areas were considered as areas that connect the paths and therefore form part of the network. 
Once carefully constructed the spatial model, the configurational analyses can be performed. The analysis used in this study is angular analysis (Al-sayed et al., 2014), which attributes a value to each stretch of path in relation to: its topological distance with respect to all the other paths, the number of connections with respect to the nearest paths, the angle of intersection between the segments, and the range of local action (Fig.4). This analysis resulted in some parameters, one of which was Choice (probability of choice) of the paths system, a parameter used in this study.

The various software used for the analysis represent an integrated system so that the information collected is easy to transfer, process and communicate to the outside. This system was created to contain a database of information on which to work and draw from according to the processing to be done. This system is formed of software mainly developed by the Space Syntax research group to analyse spatial configurations (Depthmap and Confeego), as well as statistical software (JMP and Excel), GIS software (Mapinfo) and design software (Autocad).

The result of the configurational analysis can be read on the maps which show different levels of usability in the park. In particular, the map in Fig.5 shows movements 'through' according to a colour scale that changes from blue to red based on the value of the Choice parameter: red shows connections that unite the different areas of the park and they are more accessible based on their "configuration". Some important factors emerged, such as: i) to the south, the ring formed by long waterways (the Navicelli canal - the Arno River - the coast), ii) the connections between the Estates into which the park is divided, which are found along the edge of the park or outside its boundaries (Tombolo Estate San Rossore Estate - Migliarino Estate).

This map was used to choose the main paths on which to carry out the performance analysis. As already mentioned in paragraph 2 this sub-system was identified in all those segments that have a choice value that exceeds $70 \%$ of the maximum value calculated in the case in question. The main routes are those potentially more visible to the user and more interconnected and therefore those which require verification of the performance and environmental accessibility conditions.

\subsubsection{The performance analysis}

The performance analysis involved a first phase in which a working group comprised of experts of design for all analysed the requirements framework of the following user profiles: people who use wheelchairs with manual traction, people who use wheelchairs with electric traction, accompanied blind people, and blind people who use a long cane. The purpose was to structure an integrated evaluation system of the accessibility of the network of paths in the park mainly verifying the degree of practicability of the same, that is the capacity to be used safely, guaranteeing users the possibility of fully experiencing the different environmental components of the area.

The group developed a survey tool - data collection sheets - and a verification check list containing specific techniques including those relating to existing regulations: the transport hub system (car parks, stopping and pick-up points, public transport etc.), types of paths (widths, slopes, type of paving, surface recognizability, territorial sections), the presence of obstacles, the presence of facilities and obstacles (furniture, equipment, etc.), type of signage (synoptic, directional, didactic, prohibitions, etc.) (Fig. 6). The check list is broken down into a series of questions on the existence or lack of physical and/or perceptive barriers.

The survey phase was conducted with a series of targeted inspections, carried out in homogeneous weather conditions by a group made up of both validators, that is people belonging to the paradigmatic categories of user taken into consideration, as well as data collectors, namely technical personnel who collected the data during the survey phase and systematized it in the subsequent information reorganization phase (Fig.7). The data collection forms were inferred 
from an analysis of the state of the art in relation to studies on accessibility in parks (Nesi and Bagnato, 2005; Lancerin, 2003; US Forest service, 2013; Zeller et al., 2012; Priskin 2001; Alaeddinoglu and Can, 2011), and organized into three macro areas. The first concerns the analysis of use behaviour by users observed along the sections of the paths examined, an analysis of the stops made, and the partial and total use times. The survey was carried out with the help of GPS devices which traced the planimetric and altimetric movements made by the data collectors. The second part concerns the analysis of the geometric and technical aspects of the "practicable" spaces, namely all the components that characterize the marked pedestrian paths, with the collection of geometric typologies and dimension and qualitative parameters, such as: the type of paving, systems to overcome unevenness, methods to construct suspended paths or elevated walkways, forced passages (gates and narrow stretches), methods for creating dividers and hand railings if required, recognition systems for pedestrian surfaces, with particular attention to the needs of blind people (natural or artificial lines and points of reference). The third part concerns the analysis of the services and equipment provided, in particular surveys were made of both rather common furniture (such as chairs, tables, any toilet facilities) and specialist areas mainly linked to observing the flora and fauna found along the nature trails, such as birdwatching huts, panoramic viewpoints, etc. One particular section of the third part concerns the analysis of signage and information systems, especially those dedicated to blind people, with Braille systems and tactile maps so they can recognize places and objects. The sheet also contains a plan of the route accompanied by standard sections.

Each survey was commented on pointing out, for each stretch of path analysed, the strengths or weaknesses, including metric measurements, photos and video footage with comments by the disabled people involved in the study, who thus also perform the task of validators of the correctness of the survey tools.

The data detected and collected on the sheets was then processed according to a score system ranking from 1 to 6 to assess the degree of difficulty of accessing the network of paths according to the category of user (1 indicates the most accessible path and 6 the least accessible). Separate maps were created which reconstruct a synoptic framework of the accessibility conditions for wheelchair users and blind people according to 6 degrees of accessibility established in relation to the level of autonomy of the user: path independently accessible to a person with motor or perceptual difficulties (1), path accessible with assistance from a person who provides support in conditions of localized difficulty (such as areas where it is difficult to manoeuvre) (2), path accessible with the support of a helper capable of intervening in the user-environment relationship (such as routes in which there are diffused conditions of difficulty, hard to overcome autonomously) (3), path only accessible with the support of a helper capable of intervening in the userenvironment relationship (such as routes in which there are diffused conditions of difficulty that may cause dangers and can only be overcome with the help of a dedicated helper) (4), path difficult to navigate even with the help of a dedicated helper (5), inaccessible path (6).

By overlapping the data and applying a process of reducing the degree of accessibility to the most unfavourable conditions, a joint accessibility map was defined representing the needs of the different categories of users considered (blind people, wheelchair users) (Fig.8).

\section{Results and Discussions}

The routes selected as having the greatest probability of being used by visitors, according to what was said in 3.2.1, on which the surveys and evaluations of the performance analysis were based, as outlined in 3.2.2, were used, finally, to calculate the environmental accessibility indicator of the path $G_{\text {apath }}=\mathrm{I} / \mathrm{b}^{*} \mathrm{~A}$, illustrated in paragraph 2 , which is also represented by a map that uses colours to describe a scale of values (Fig. 9). 
The "degree of environmental accessibility" is expressed by a colour scale ranging from blue (lowest value) to red (highest value) associated with the $\mathrm{Ga}\left(\mathrm{I} / \mathrm{b}^{*} \mathrm{~A}\right)$ values for every single path. The map therefore represents the most accessible paths (in red, orange and yellow), as they are potentially the most accessible paths to users as in themselves they represent a good connection to all the other paths in the network, and as they are paths free, or almost free, of physical barriers for weak users. The blue, light blue and green paths are the ones potentially most accessible to the public as in themselves they represent a good connection, but they present physical impediments along them. In the case study examined the maximum value of $\mathrm{Ga}\left(\mathrm{I} / \mathrm{b}^{*} \mathrm{~A}\right)$ calculated for every single segment of path is 664 and the minimum value 0.01 . Considering the segments that have a Ga value exceeding the $50 \%$ threshold $(\mathrm{Ga}=322)$ of the maximum value calculated in the case in question, note how they represent only one tenth $(19 \mathrm{~km})$ of all the segments inspected $(229 \mathrm{~km})$.

From the perspective of the approach followed and proposed as a reference framework verified in the case study, the configurational analysis, carried out on the entire system of public paths in the park, enabled us to identify the subset of pedestrian paths on which to conduct a subsequent performance analysis of the accessibility conditions for specific categories of users, limiting only to these paths the survey and evaluation phase, which requires time and means involving resources in inspections. The combination of the configurational and performance analyses made it possible to produce a numeric indicator represented by a map that use colours to describe a scale of values. This spatialization of the indicator appears to be a good means of communication above all when the spatial localization of the data is important, as was the case in the study examined.

The purpose of the accessibility indicator applied to the pedestrian paths network of the park and the method with which it was constructed provide information useful for planning and managing activities, taking the park's institutional objectives into account, which may be summed up by the protection and enhancement of the park's natural heritage. This information can be read on two levels: i) the possibility of comparing the degree of accessibility of parks with similar characteristics; ii) the possibility of identifying circumscribed areas on which to assess the degree of improvement deriving from activities carried out or planned by the organization that manages the park.

In the first case the data of the average weighted value of accessibility or the value of the highest percentile, as presented in paragraph 2, can be used as accessibility classification criteria for parks with similar characteristics (the same Functional Equivalent). In the second case the maps with colours that describe the scales of the accessibility values of the trails provide spatially located information that is easy to communicate.

The methodology, indicators and results of the analyses conducted according to the process outlined in this study can be a tool to promote regional policies to support the improvement of accessibility in natural parks, and they can also be a tool for the monitoring and planning of interventions in the management plan of a park. An example of a management plan referred to the case study is given in Fig. 10 where the map provides two types of information: the intervention priorities and the maintenance control and verification priorities. The intervention priorities are assessed on the basis of the need to improve the degree of accessibility of the paths based on criteria that help to define the degree of accessibility including the provision of services and signage. The priorities relating to control and maintenance activities are defined according to two levels based on the geometric and technical characteristics of the paths and the duration over time of the performance levels.

\section{Conclusions}


Natural parks, insofar as a resource for sustainable development, have social value in themselves and are subject to impact assessment in this regard too. As part of these assessments, for parks that do not represent a nature reserve or wilderness area, the issue of accessibility for all of the network of internal paths is considered a priority, but an analysis methodology capable of addressing such a complex matter, which refers to very different needs and involves different expertise, has still not be defined or recognized. The case study of the Natural Park of Migliarino, San Rossore and Massaciuccoli in Tuscany (Italy) offered many significant aspects pertaining to the relevance of the theme, and the study presented here applied to this case has allowed us to verify an analysis method and an accessibility indicator. To this end, we made use of the configurational analysis techniques of Space Syntax and the performance analysis techniques referred to the physical barriers found along the paths. These techniques employ a needs-based approach and were applied by conducting not only surveys on the configuration and characteristics of the paths, but also observations of the behaviour of people with different levels of physical ability to travel along the walkways in the park; moreover, people were involved and asked to give their opinion on the degree of environmental accessibility of the paths. Therefore, the combination of the two analysis techniques allowed us to prepare an indicator responsive to and driven by users needs for each segment of the network of paths in the park.

In order to communicate the results of the analysis it was decided to translate the numeric indicator attributed to each segment of the network of paths in the park into a map that uses colours to describe a scale of values attributed to the indicator.

The stakeholders (operators in the park and people involved in the observations and assessments) were able to verify, using the maps prepared in this way, the degree of comprehensiveness of the information produced by the study and provide validation of the method proposed.

The method aims to represent a tool for managing the policies to improve the "accessibility for all" conditions of the trails that represent the network of paths open to the public in a natural park, both at regional policy level, which concerns plans to promote the social value of the park, and at the level of management plans for individual parks to evaluate the priority interventions to improve the accessibility conditions.

Some limits to this study concern the fact that the indicator proposed involves a complex process of modelling the system studied and a large number of observations, surveys and measurements. As for the modelling, it is clear that the complexity only concerns the start of the study and not any subsequent updates. As for the direct surveys to be conducted in the performance analysis phase, the fact that the configurational analysis is carried out first means the findings can be circumscribed directly to a sub-system of paths thereby reducing the work load of carrying out the surveys.

Moreover, in the study conducted the involvement of experts and disabled people was high, and with its application to several case studies it will be possible to establish "robust" correlations between objective data describing the network of paths and subjective data that includes opinions expressed by experts and disabled people, thereby reducing the need for direct involvement each time and refining the 'characterisation' of the parameters in relation to the perceived quality.

There is still a long way to go before the methodologies and operational procedures for this type of social analysis can be set out considering the complexities of data collection, the characterization of parameters and the involvement of stakeholders and experts. For this reason, this type of investigation using case studies may offer significant contributions if viewed as experimental laboratories.

\section{Acknowledgments}


The authors would like to thank A. Gennai, A. Porchera and Susanna Paoli from the MSRM Park Administration for their assistance; the accessibility surveys group (Elisabetta Bertuccelli, Roberta Bernardini, Elisabetta Biagioni, Stella Bianchini, Luca Cesaretti, Melissa Fanucchi, Francesca Furter, Piero Lorenzetti, Antonella Marcucci, Roberto Pardini, Giuseppe Parisi, Jani Plauschku, Federico Sebastiani.); and Rebecca Milner for English language services.

\section{Funding}

The research was supported by PRIN (National Research Program Italy 2009-2010 - final report 2013)

\section{References}

AA.VV. (1988), Access America. An Atlas and Guide to the National Parks for Visitors with Disabilities, Northern Cartographic, Burlington, Vermont 1988.

Alaeddinoglu F. and Can A. S. (2011), Identification and classification of nature-based tourism resources: western Lake Van basin, Turkey, Procedia Social and Behavioral Sciences 19 (2011) 198-207

AL-SAYED, K., TURNER, A., HILliER, B., IIDA, S. and PENN, A. (2014) Space Syntax Methodology. 4th edition. London: Bartlett School of Architecture, UCL.

Aragall, F. (2003), European Concept for Accessability. available at: http://www.ub.edu/escult/Water/N05/eca_full.pdf.

Aragall F., Sagramola S. (2003), Chapter 2 - People-centred approach, in: The European Concept For Accessibility Technical Assistance Manual 2003, EuCAN c/o Info-Handicap Luxembourg, available at: http://homepage.eircom.net/ 1idd/

A/RES/55/2: United Nations Millennium Declaration: resolution adopted by the General Assembly. 55/2. Sept 18, 2000 .

Bowen, RE and Riley, C (2003) Socio-economic indicators and integrated coastal management: Ocean \& Coastal Management [Ocean Coast. Manage.]. Vol. 46, no. 3-4, pp. 299-312. 2003.

Burkhard B, De Groot R, Costanza R, Seppelt R, Jørgensen SE, Potschin M (2012) Solution for sustaining natural capital and ecosystem services. Ecological Indicators Vol21:1-6

Carson, R., (1962), Silent Spring, Houghton Mifflin USA

Chipi-Shrestha GK, Hewage K, Sadiq R (2015) 'Socializing' sustainability: a critical review on current development status of social life cycle impact assessment method. Clean Technologies and Environmental Policy 3:579-596

Clius M., Teleucă A., David O., Moroşanu A. (2012) Trail accessibility as a tool for sustainable management of protected areas: Case study Celahau National Park, Romania. Procedia Environmental Sciences 14 (2012). 267 - 278

Costanza R, d'Arge R, de Groot R, Farber S, Grasso M, Hannon B, Limburg K, Naeem S, O'Neill RV, Paruelo J, Raskin RG, Sutton P, van den Belt M (1997) The value of the world's ecosystem services and natural capital. Nature 387:253260

Dale, A., Taylor, N. and Lane, M., eds., (2001). Social assessment in natural resource management institutions.

Collingwood, Victoria: CSIRO Publishing.

Di Cesare S., Silveri, F., Petti L., (2015). Positive impacts and Indicator Categories in Social Life Cycle. Assessment. Results from a systematic review, in: Sala, S., Vasta, A., Mancini, L., Dewulf, J., Rosenbaum, E. (eds.) 2015, Social Life Cycle Assessment - State of the art and challenges for supporting product policies. European Commission, Joint Research Centre, Institute for Environment and Sustainability, Publications Office of the European Union, Luxemburg pp. 46-53 Available at http://publications.jrc.ec.europa.eu/repository/bitstream/JRC99101/lbna27624enn.pdf

Dreyer LC, Hauschild MZ, Schierbeck J (2006) A Framework for Social Life Cycle. Int J Life Cycle Assess 11(2): 8897

Dudley N (2008) IUCN Guidelines for Applying Protected Area Management Categories. www.iucn.org/pa_categories. Accessed 19.08.2014

EEA (1999), Technical report n.25, Environmental indicators: Typology and overview, EEA Copenhagen

EC (2010) European Disability Strategy 2010-2020: A Renewed Commitment to a Barrier-Free Europe. Available at http://eur-lex.europa.eu/legal-content/IT/TXT/?uri=celex\%3A52010DC0636

EC-JRC-IES (2010), General guide for Life Cycle Assessment - Detailed guidance, EUR 24708 EN, Luxembourg Publication Office of the European Union 
EN 15804:2012 Sustainability of construction works, Environmental product declarations, Core rules for the product category of construction products

ENEA (2001), Applicare la norma UNI EN ISO 14001 nelle aree protette, UNI - Serie Gestione Ambientale Linee Guida, Milano

Esteve AM, Franks D., Vanclay F., (2012), Social impact assessment: the state of art. Impact Assessment and Project Appraisal, 30 (1): $34-42$

Farrington J. H. (2007), The new narrative of accessibility: its potential contribution to discourses in (transport) geography, Journal of Transport Geography 15 (2007) 319-330

Gates T., Noyce D., Bill A., and Van Ee N. (2006) Recommended Walking Speeds for Pedestrian Clearance Timing Based on Pedestrian Characteristics. In: Transportation Research Record: Journal of the Transportation Research Board, Volume 1982. pp.38-47

Gondran N (2012) The ecological footprint as a follow-up tool for an administration: application for the Vanoise National Park. Ecological Indicators 16:157-166

Grießhammer R, Benoît C, Dreyer LC, Flysjö A, Manhart A, Mazijn B, Méthot AL, Weidema B (2006) Feasibility Study: Integration of social aspects into LCA. Öko-Institut, Freiburg

Habitats $\quad$ Directive 92/43/EEC available at http://ec.europa.eu/environment/nature/legislation/habitatsdirective/index_en.htm

Hillier B, (2007) Space is the machine: a configurational theory of architecture. Space Syntax, London

Hillier B, Hanson J (1984) The social logic of space. Cambridge University Press, Cambridge

Hillier B, Iida S. (2005) Network and psychological effects in urban movement. In: Cohn A, Mark D (eds) Proceedings Spatial information theory: International conference. COSIT, LNCS, Springer-Verlag, Berlin, 475-490

Hillier B, Raford N (2010) Description and discovery. In Socio-spatial Analysis: The case of Space Syntax in Walford $\mathrm{G}$ et al (eds) The sage handbook of measurement. SAGE, London

Hillier, B; Vaughan, L; (2007) The city as one thing. Progress in Planning, 67 (3) pp. 205-230.

Ielasi R, Incagli M, Masone M (2003) Linee Guida per l'applicazione del modello EMAS a parchi e aree naturali protette, Manuali e linee guida 24/2003, APAT. Available at: http:/www.isprambiente.gov.it/contentfiles/00003500/3504-manuali-2003-24.pdf/ . Accessed 20 June 2017

ISO (International Organization for Standardization) (2010a). ISO 26000:2010 Guidance on social responsibility, Geneva, Switzerland: ISO

ISO (International Organization for Standardization) (2010b). ISO 21931-1 2010, Sustainability in building construction - Framework for methods of assessment of the environmental performance of construction works - Part 1: Buildings.

IUCN UNEP WWF (1980) Word conservation strategy. Living resources conservation for sustainable development.

IUCN. 2017. IUCN Protected Areas Categories System http:/www.iucn.org/about/work/programmes/gpap home/gpap quality/gpap pacategories/ (accessed 04.07.2017)

Kareiva, P., Tallis, H., Ricketts, T.H., Dayly., G., Polasky, S., (ed.s) (2011), Natural Capital: Theory and Practice of Mapping Ecosystem Services, Oxford University Press

Knoblauch R., Pietrucha M., Nitzburg M. (1996), Field Studies of Pedestrian Walking Speed and Start-Up Time. In: Transportation Research Record: Journal of the Transportation Research Board. Volume 1538. pp.27-38

Lancerin L. (ed by) 2003, Il verde è di tutti - Schede tecniche per la progettazione e la realizzazione di aree verdi accessibili e fruibili, Regione Veneto. Available at: http://www.edscuola.it/archivio/handicap/verde.pdf

Lauria A (2017) Environmental design \& accessibility: notes on the person-environment relationship and on design strategies, Techne - Journal of Technology for Architecture and Environment, 13.

Levi Sacerdotti, S., Rosa, A., Mauro, S., Cavallero, M., Brandais, F., Gasca, E., Pollichino, G., Beltramo, S. (2010), "Il progetto di visitor management per lo sviluppo turistico della regione Piemonte: il caso della valle di susa", XXXI Conferenza Italiana di Scienze Regionali.

Magnaghi, A. (a cura di) (1998), Il territorio degli abitanti. Società locali e auto sostenibilità, Dunod, Milano. 
Millenium Ecosystem Assessment (2005), Global Assessment report. http://www.millenniumassessment.org/en/Global.html. Accessed 20 June 2015

MATTM - Ministero dell'Ambiente e della Tutela del territorio (2003) Parchi per tutti Fruibilità per un'utenza ampliata. Linee guida per gli enti di gestione dei Parchi Nazionali italiani. Editoriale AESSE, Roma http://www.minambiente.it/sites/default/files/archivio/biblioteca/dpn_linee_guida_parchi.pdf. Accessed 20 June 2017

Moine, A. (2006), "Le territoire comme un système complexe: un concept opératoire pour l'aménagement et la géographie”, L'Espace géographique, Vol. 2 (35), pp. 115-132.

Nesi A. and Bagnato F. (2005), Progetto per incrementare la fruizione dei parchi nazionali a fasce di cittadini deboli, di, Edizioni Gangemi

OECD (Organization for Economic Cooperation and Development) (1998). Towards sustainable development: environmental indicators. Paris.

Penn A (2003), Space Syntax and spatial cognition or why the axial line? Environment and Behavior 35(1):30-65

Penn A (2008), Architectural research. In: Knight A, Ruddock L (eds) Advanced research methods in the built environment. Wiley-Blackwell, Oxford

Priskin J (2001), Assessment of natural resources for nature-based tourism: the case of the Central Coast Region of Western Australia, Tourism Management 22 (2001) 637-648

Rapley Clinton E., (2013), Accessibility and development: environmental accessibility and its implications for inclusive, sustainable and equitable development for all, Report developed in collaboration with United Nations Agencies, Disabled Person Organization (DPO)

Regione Lazio (2006), Il Parco Accogliente. Fruibilità e Accessibilità delle Aree Protette del Lazio, Quaderni tecnici dei parchi del Lazio, available at: http://arplazio.it/documenti/schede/3352_allegato1.pdf (last access June 2017).

Salzau Message (2010) Sustaining natural capital and ecosystem services. http://www.unikiel.de/ecology/projects/salzau/uncategorized/\%E2\%80\%98salzau-message $\%$ E2\%80\%99-on-sustaining-ecosystemservices-and-natural-capital/ . Accessed 20 Juin 2015

SEBI (2010) Assessing biodiversity in Europe - the 2010 report. Technical report No 5/2010 EEA publisher

SEBI (2012) Streamlining European biodiversity indicators 2020: Building a future on lessons learnt from the SEBI 2010 process. Technical report No 11/2012 EEA publisher

Steffan, I. T. (a cura di) (2012), Design for All - Progetto per tutti, metodi strumenti ed applicazioni Vol I, Maggioli Editore, Santarcangelo di Romagna (RN).

Solinas, M. (a cura di) (2004), Accessibilità e fruibilità delle Aree Protette, Roma.

Thwaites, K. and Simkins, I.M. (2007), Experiential Landscape: an approach to people, space and place, Routledge, Oxon.

Torricelli, M.C. (Ed) (2015). ES-LCA e patrimonio naturale. Life Cycle Analisi ambientale e sociale di un'area protetta. FUP Firenze Italy

UNESCO 2017. A New Roadmap for the Man and the Biosphere (MAB) Programme and its World Network of Biosphere Reserves, available at http://unesdoc.unesco.org/images/0024/002474/247418E.pdf

US Forest Service (2013) Outdoor Recreation Accessibility Guidelines. Scoping Requirements, Technical Provisions, and Appendix (FSORAG), e Trails Accessibility Guidelines (FSTAG), Washington, D.C. 2013

WCED (World Commission on Environment and Development) (1987), Our common future, Oxford University Press, Oxford.

Zeller, J. Doyle, R. Snodgrass K. (2012) Accessibility Guidebook for Outdoor Recreation and Trails, a cura di U.S. Department of Agriculture Forest Service Technology \& Development. Available at: www.fs.fed.us/recreation/programs/accessibility/pubs/pdfpubs/pdf12232806/pdf12232806Pdpi100pt01.pdf

Zhai, Y. and Baran, P. (2013), “Application of Space Syntax theory in study of urban parks and walking”, Kim, Y.O., Park H.T. and Seo, K.W. (Eds), Proceedings of the Ninth International Space Syntax Symposium, Sejong University, Seoul, pp. 032:01-13. 


\section{FIGURES CAPTIONS}

Fig. 1 - The boundaries of the system

The boundaries of the system observed are defined by: external transport and external access hubs, internal points of interest, internal paths network, and the external paths complementing the circuits or for pedestrian access

Fig. 2 - The MSRM Park area

The MSRM Park area in Tuscany overlooking the Tyrrhenian Sea is crossed by the Arno and Serchio rivers, the regional railway and a high-speed road, with the main and secondary trails network

Fig. 3 - Methodological process for the definition of the Ga indicator

Graphic representation of the integration between performance approach and spatial configurational approach in defining the environmental accessibility indicator

Fig. 4 - Configurational approach

Relationship between configurational parameters and usability, accessibility, experience of the park

Fig. 5 - Configurational accessibility

Map of the park's most accessible paths according to configurational analysis (Space Syntax segment analysis- Choice Rn). The colour scale changes from blue to red based on the value of the Choice parameter

Fig. 6 - Extract of the data collection sheet

Summary of paths typological analysis (widths, slopes, type of paving, surface recognizability, territorial sections) and evaluation of pathway and services (presence of obstacles, presence of facilities as furniture and equipment, type of signage)

Fig. 7 - The group of validators

The group was made by people belonging to the paradigmatic categories of user taken into consideration (Blind people, people with guide dogs, people on wheelchair), as well as data collectors, namely technical personnel who collected the data during the survey phase and systematized it in the subsequent information reorganization phase

Fig. 8 - Degree of accessibility to the most unfavourable conditions

Summary map of the trails evaluated showing the accessibility levels: from high full autonomy to low unavailable

Fig. 9 - Map of the environmental accessibility indicator

The map represents the values of Ga indicator analysis using colours to describe a scale of values for each path evaluated by configurational and performance

Fig. 10 - Example of Park's Management Plan and Seal Tracking Plan

The map provides two types of information: the intervention priorities and the maintenance control and verification priorities 


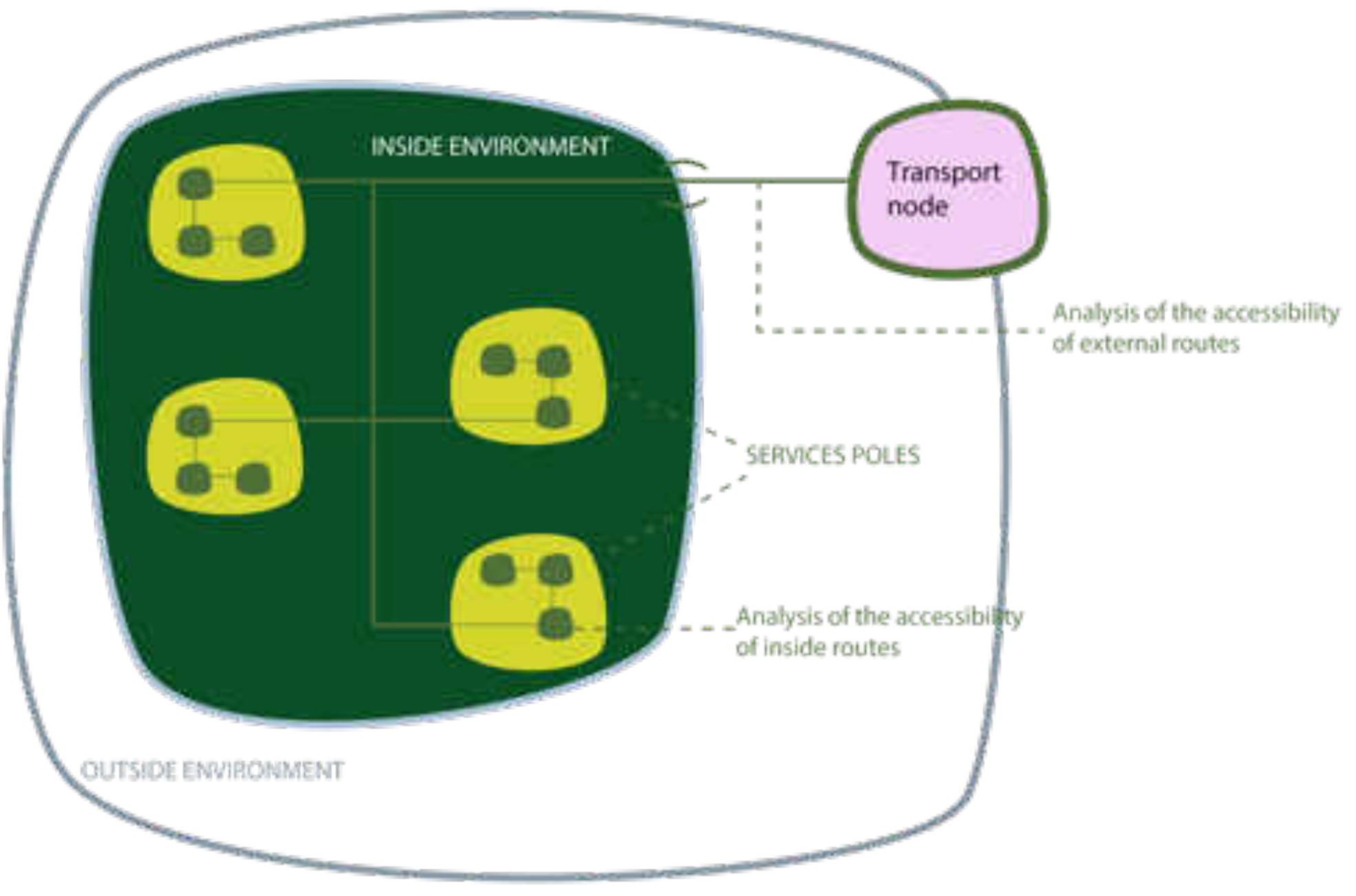




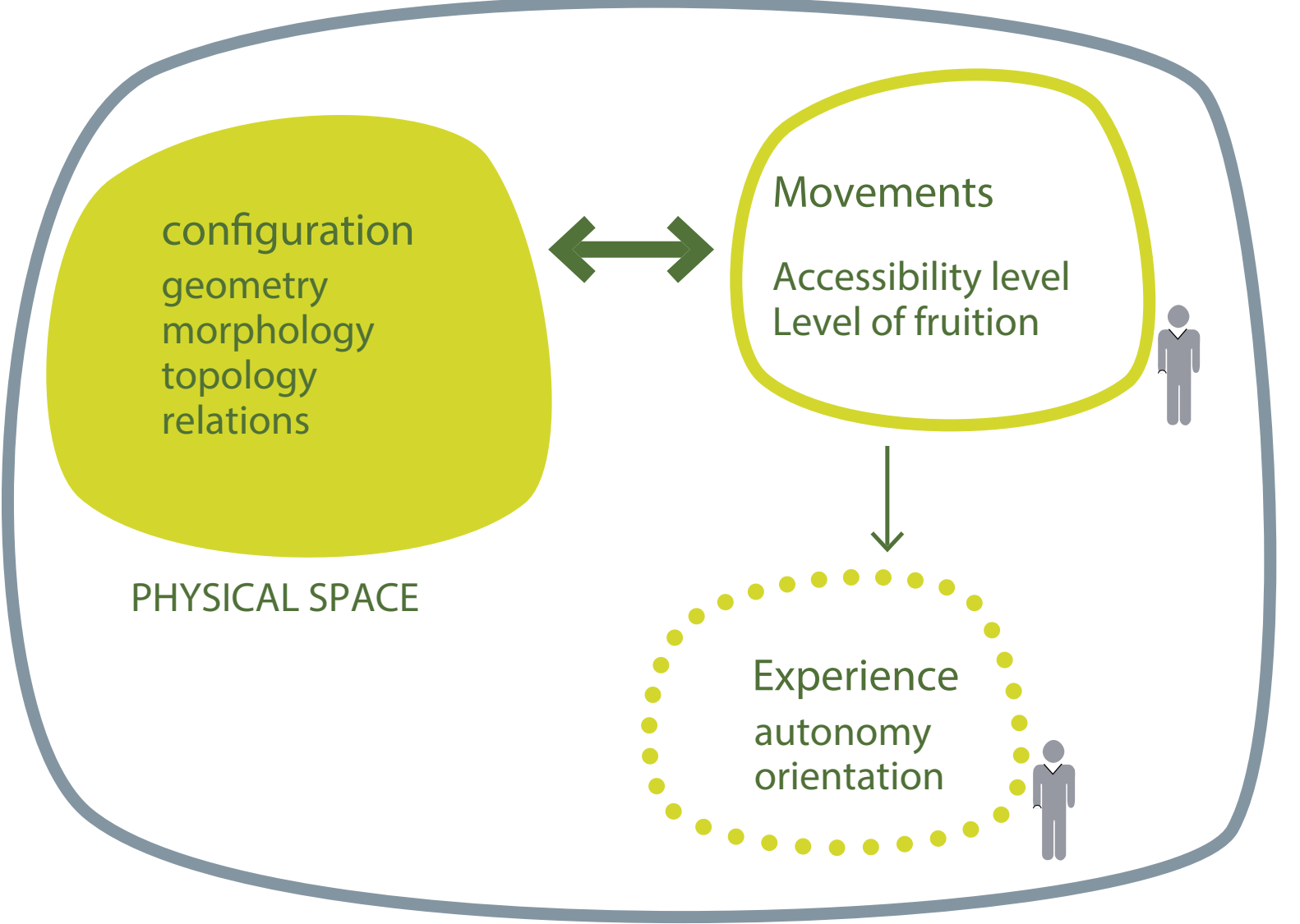

ENVIRONMENT 

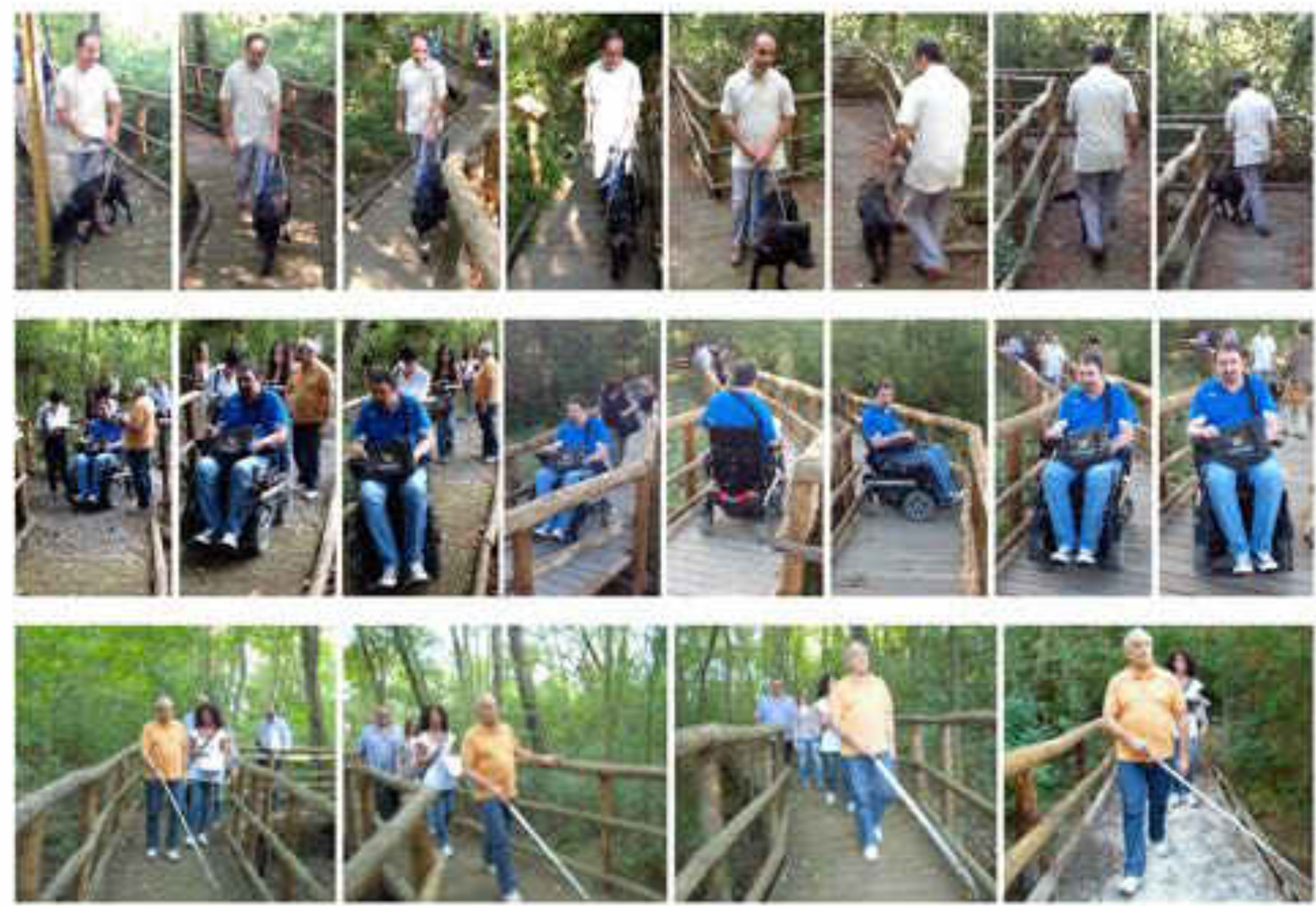


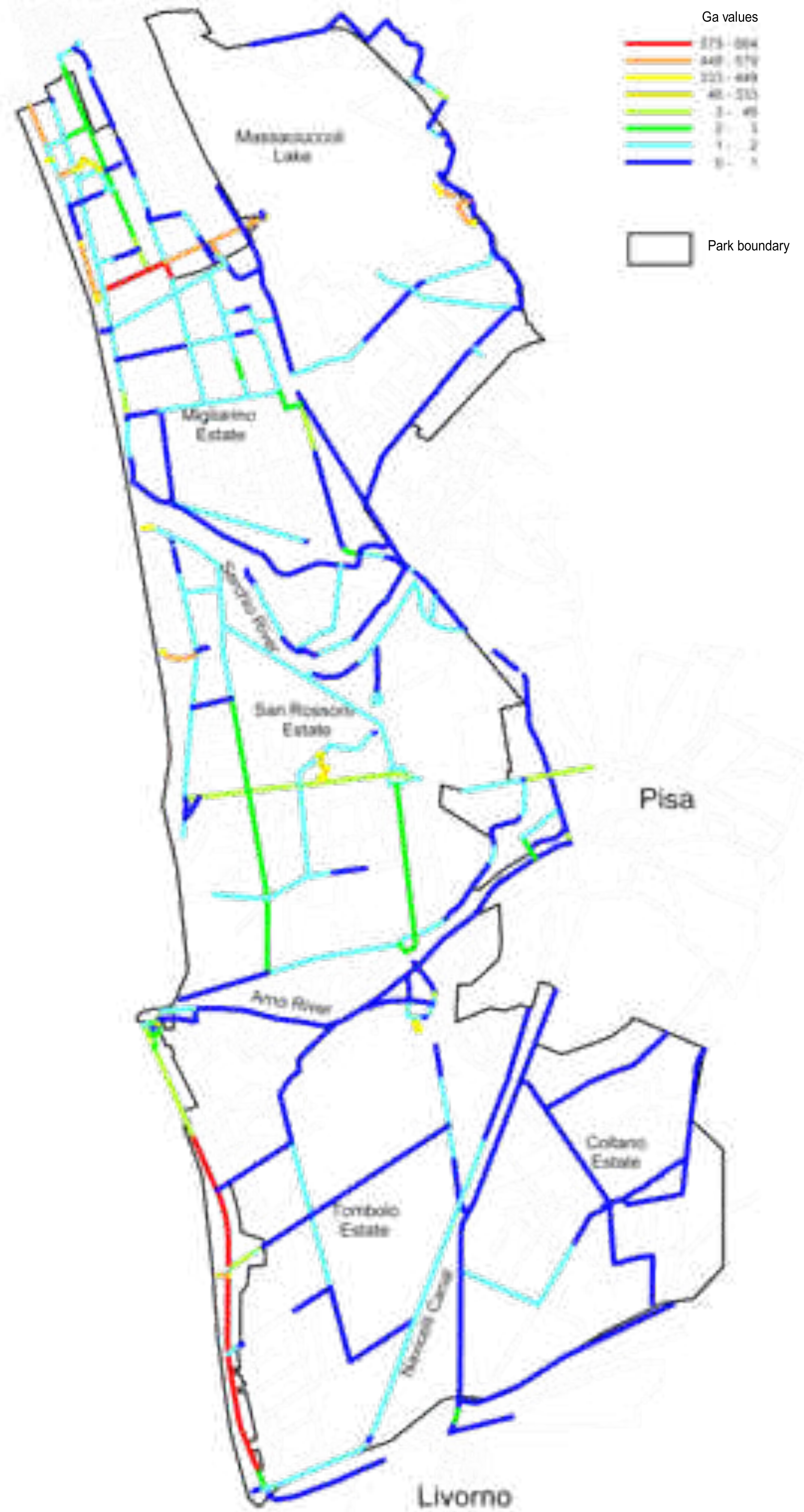




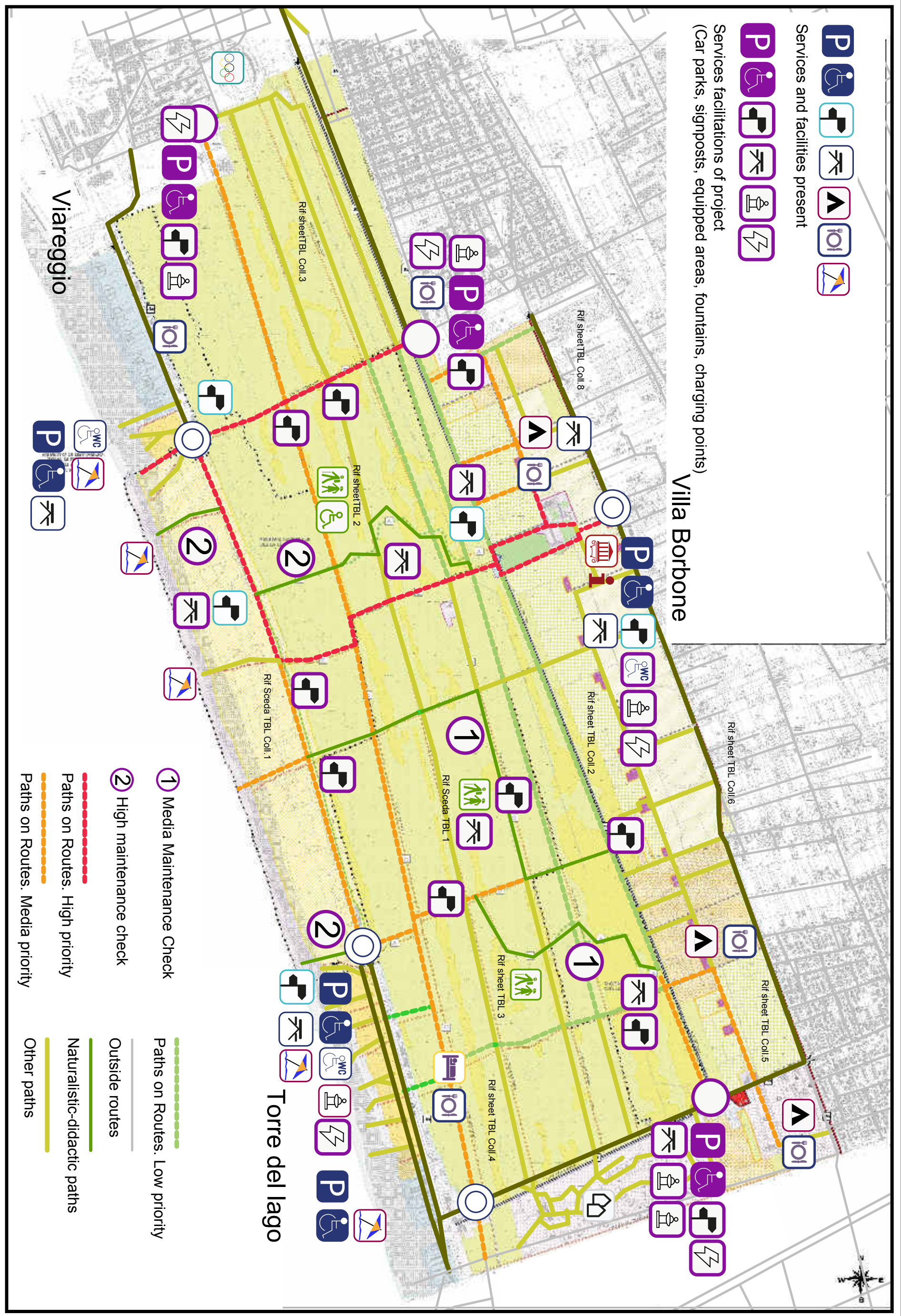




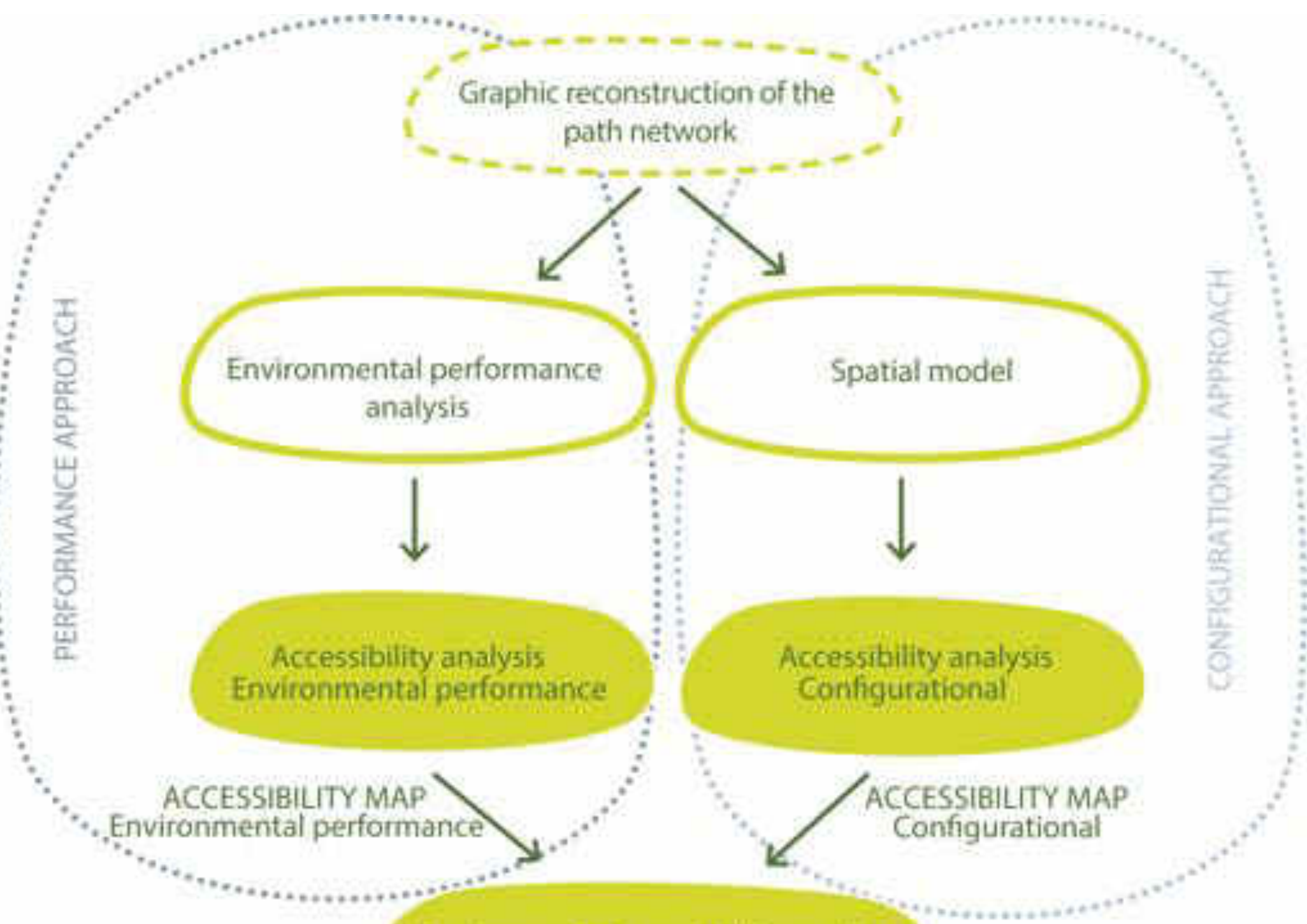

Environmental accessibility analysis

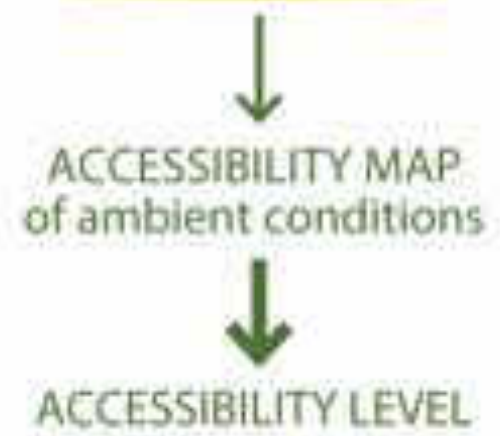




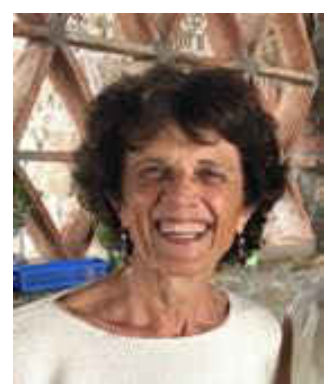

\section{Maria Chiara Torricelli}

Full Professor on Architectural Technology at University of Florence. Main research lines are Social buildings (health, residential and school buildings); Building systems Innovation, Performance Based Design; Sustainability of Built Environment. She was Expert Member of the CEN TC 350 Sustainability of Construction Works (2008-2014) and of UNI WG of the Commission Sustainability in Construction Processes, Products and Systems (2008-2014), member of the technical group of ITACA for Italian ecolabels for buildings (2012-2016). Involved in many researches published in books and scientific journals, is Editor of the book ES-LCA e patrimonio naturale. Life Cycle Analisi ambientale e sociale di un'area protetta (2015).

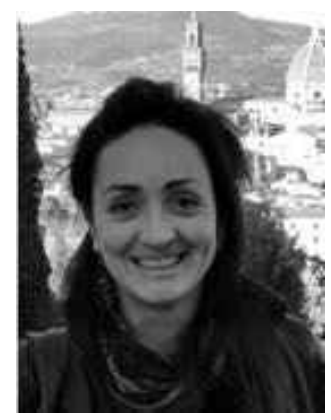

\section{Nicoletta Setola}

Architect (2003), PhD in Architectural Technology and Design at University of Florence (2009), Assistant Professor (2016) with license for Associate Professor at the Department of Architecture. Her research focuses on the topic of socio-healthcare building, particularly on functional analysis in complex architectural project. She is expert in methodology and tools for the spatial configuration analysis related to people flow in the built environment. She is involved in the EU COST Action IS1405 BIRTH. Her last book published by Routledge in 2016 is Designing Public Spaces in Hospitals.

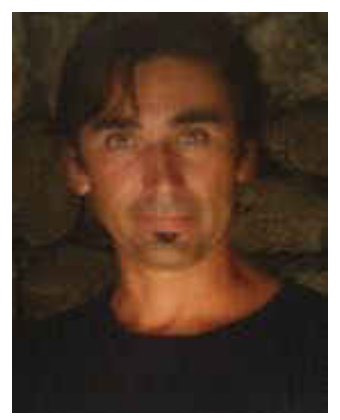

Luca Marzi

Degree in Architecture (1994) at University of Florence and PhD in (2010) with a thesis dealing on Accessibility in Healthcare Facilities. He has carried out design and consulting activity for public authorities focusing on accessibility and usability. He has carried out research activity dealing on management system of information related to accessibility. Since 1999 he is researcher at Department of Technology for Architecture and Design of University of Florence. 
Particularly he is envisaged in the Monitoring Laboratory for the refurbishment of the Florence University Hospital. He has published scientific paper and articles on the following topics: design for all, management and monitoring systems for complex projects. 